Powder Metallurgy and Metal Ceramics, Vol. 45, Nos. 3-4, 2006

\title{
POWDER METALLURGY OF BERYLLIUM: THE DEVELOPMENTS OF THE NATIONAL SCIENTIFIC CENTER “KHAR'KOV PHYSICOTECHNICAL INSTITUTE"
}

\author{
A. V. Babun, I. M. Neklyudov, V. M. Azhazha, \\ K. V. Kovtun, A. A. Vasil'ev, and G. G. Bobylev
}

UDC 621.762

For the first time in the production of construction beryllium an integrated technology for the production of a new generation of high-purity isotropic materials has been developed and mastered. The technology combines processes of vacuum distillation of the metal, gas flow atomization of a melt, specialized processing of the powder prior to densification and hot isostatic pressing. A technology for the production of spherical powders of beryllium and beryllium-based alloys by atomization of a melt is also developed and employed for the first time. A technology is developed and optimal conditions of isostatic pressing of spherical powders are determined. Isotropic beryllium with high physico-mechanical characteristics is obtained. The properties of the materials thus obtained are studied. The strength of the new materials is $20 \%$, and their plasticity two to three times greater, than commercial beryllium. It is shown that the high purity of the initial powder, the cellular structure, uniform distribution, and dispersity of the particles of beryllium oxide and segregations of secondary phases are the principal factors that govern the level of the properties of compact beryllium materials.

Keywords: physical metallurgy of beryllium, powder, technology for production of beryllium, atomization of a melt, hot isostatic pressing, physico-mechanical properties, isotropicity, cellular structure.

In recent decades a scientific school in the area of the physics and technology of beryllium has been created at the National Scientific Center "Khar'kov Physicotechnical Institute." In the course of developing and extending previously performed investigations, the most important problems have been solved. The solutions to these problems have made it possible to expand the range of use of beryllium, turning it into an irreplaceable material of aerospace technology, instrument construction, and nuclear and thermonuclear power engineering. However, the use of beryllium has been largely held back by its insufficient degree of plasticity, the anisotropy of the physico-mechanical properties, high internal stresses, toxicity, and high cost.

A dependence of the properties of compact metal on the grain size and the purity was established on the basis of a structure-impurity conception of the creation of the next generation of beryllium materials developed by the Khar'kov Physicotechnical Institute. It is precisely this which has served as the foundation for a new scientific approach that makes it possible to substantially improve the quality of the metal.

In recent years the isotropicity of the physicomechanical properties and thermophysical characteristics of articles has been among the basic requirements imposed on beryllium construction materials and, above all, materials used for gyroscopes and optical metals.

Near all beryllium metal is obtained by methods of powder metallurgy. The properties of cermet beryllium depend largely on the method used to produce the powder and the conditions under which it is obtained, the dispersity of the powder, the densification method, and the chemical composition of the metal. Isotropic beryllium cannot be obtained

National Scientific Center "Khar'kov Physicotechnical Institute". Translated from Poroshkaya Metallurgiya, Nos. 3-4(448), pp. 118-125, March-April, 2006. Original article submitted April 6, 2005. 


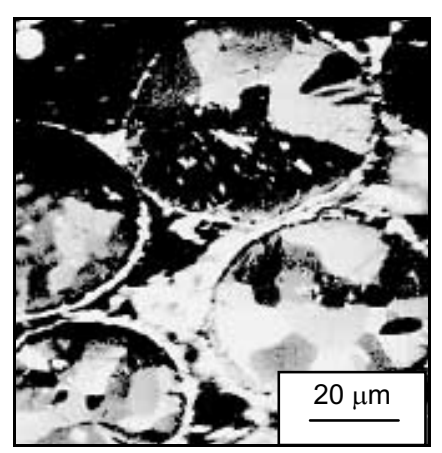

Fig. 1. Microstructure of particles of atomized beryllium powder

by means of the technology used now to produce powdered beryllium by mechanical grinding of starting material and subsequent hot compacting of the powder. This is because with mechanical grinding of powder there occurs preferred destruction of the beryllium crystals by cleavage along the basal plane (0001). The particles of the powder assume the form of plates which upon being loaded into the mold form a stacking texture which subsequent uniaxial hot compacting amplifies. Moreover, subsequent deformation of the beryllium is also accompanied by the creation of deformation texture (swaging, rolling, extrusion, etc.). Practically all types of beryllium materials that are now known are texturized to one degree or another and the properties of these beryllium materials exhibit anisotropy. Moreover, with the equipment that is used to produce active beryllium powders it is not possible to overcome the constraint signifying that "the finer the grinding, the greater the contamination of the powder."

A method of producing isotropic beryllium for optical and other applications has been created at the Khar'kov Physicotechnical Institute. The distinctive feature of the method, which has been realized from research carried out by the institute at the Ul'binsk Metallurgical Plant Production Association, lies in the use of spherically shaped beryllium powders and powders of beryllium-based alloys in combination with a process of hot isostatic pressing [1-4].

For the first time anywhere in the world high-purity beryllium powders were produced by means of atomization of a melt on an industrial scale. In this method the basic condition for forming spherical powder particles is executed with spheroidization time of the particles much less than the time needed for cooling $\left(\tau_{\mathrm{sph}}<<\tau_{\mathrm{cool}}\right)$. High rates of cooling $\left(10^{4}-10^{5} \mathrm{deg} / \mathrm{sec}\right)$ are also realized, leading to the appearance of a special quenching structure and the creation of metastable solid solutions [5].

The physical and technological chraacteristics of these powders, which are needed for purposes of modeling and realizing processes of compaction, were studied in detail. Data were obtained on the flow rate, bulk and bumping density of the powder. The shape, structure, and chemical composition of the atomized powders have been studied.

It was established that the particles of the powder possess a regular, nearly spherical shape (Fig. 1) and that their surface is smooth and possesses a characteristic metallic luster with slight dull hue. This is explained by the presence of a thin film of beryllium oxide on the surface of the particles; the film forms in the rather short period of cooling and solidification of the particles, and produces a passivizing action. Prolonged storage of the powder in open air at room temperature does not lead to any substantial additional oxidation of the powder. The structure of the beryllium particles consists of fine grains (10-15 $\mu \mathrm{m}$ in size) of arbitrary orientation. Uneven boundaries attest to the nonequilibrium structure state as well as the high internal stresses, which are a consequence of high-speed quenching of the particles.

The compressive strength of the particles of beryllium powder was studied in order to obtain data necessary for creating a mathematical model of isostatic pressing of atomized beryllium powders. For this purpose particles of controlled size were placed between the moveable posts of a testing machine equipped with a system for recording loads. The particles were subjected to deformation at room temperature at a rate of $0.8 \mu \mathrm{m} / \mathrm{sec}$. The machine was periodically halted, the load removed, and the impression area measured under a microscope. The flow stress of the material of the particles was estimated from the magnitude of the load and the impression area. The tests were conducted until complete "crumpling" of the particle was achieved or until it had disintegrated. 

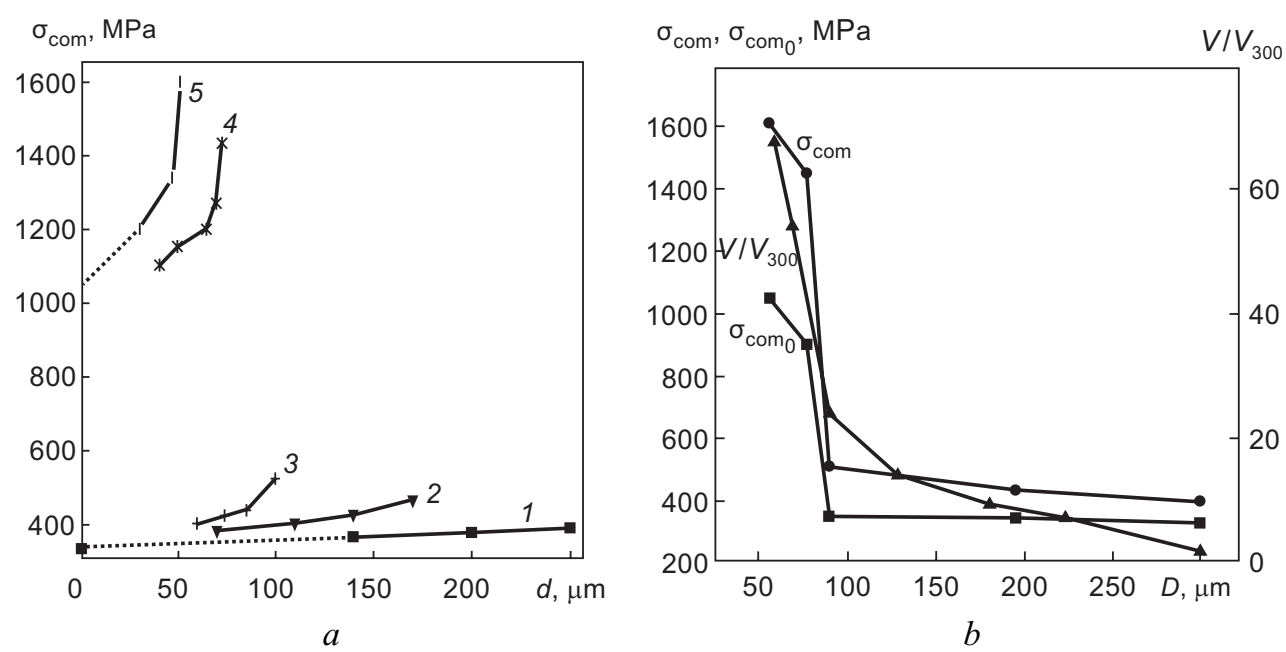

Fig. 2. Strength characteristics of atomized beryllium powder as a function of the impression size $d$ (a) and particle size $D(\mathrm{~b}): D=300(1), 195$ (2), 80 (3), 78 (4), and $57 \mu \mathrm{m}(5) ; V / V_{300}$, ratio of cooling rate of

particles of given dimension to cooling rate of particles $300 \mu \mathrm{m}$ in size

Curves expressing the dependence of the compression strength of the spherical particles of the powder on impression size $d$ are presented in Fig. 2a. It is evident that the strength of the particles grows as their size decreases. Thus, with a particle diameter less than $90 \mu \mathrm{m}$ (curves 3-5), there occurs a sharp increase in strength (to $1600 \mathrm{MPa}$ for $D=57 \mu \mathrm{m})$. It should be noted that the dependence of the strength of the particles on their size is complex in nature. Besides the effect of the structure and state of the particles matrix, which vary as a function of the quenching rate in atomization of the powder, another factor caused by the decrease in the size of the tested particle also has an effect.

The dependence of the initial compression strength $\sigma_{\mathrm{com}_{0}}$ (with $d=0$ ) and the magnitude of $\sigma_{\text {com }}$ (right up through complete crumpling of the particles) as well as the quantity $V / V_{300}$, or ratio of the cooling rate of a particle of a given size to the cooling rate of a particle $300 \mu \mathrm{m}$ in size, on the particle size $D$ is shown in Fig. $2 \mathrm{~b}$.

The substantial growth in the strength of the particles that is observed experimentally confirms their high cooling rate in atomization of the melt. The results of a study of the strength characteristics of annealed particles also points to this result. Annealing of particles $50-80 \mu \mathrm{m}$ in size at a temperature of $9500^{\circ} \mathrm{C}$ for $1 \mathrm{~h}$ is accompanied by a reduction in their strength of at most $15 \%$. The strength of particles $100-300 \mu \mathrm{m}$ in size remains practically unchanged.

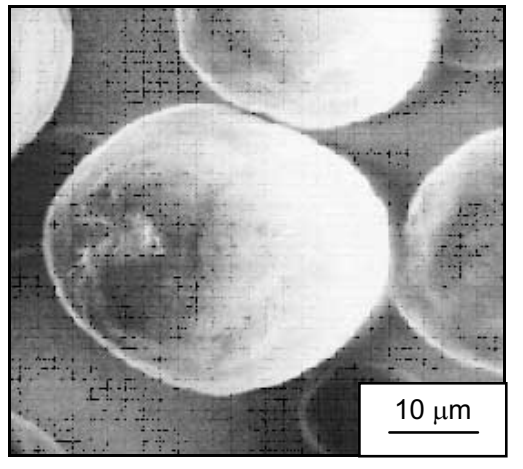

$a$

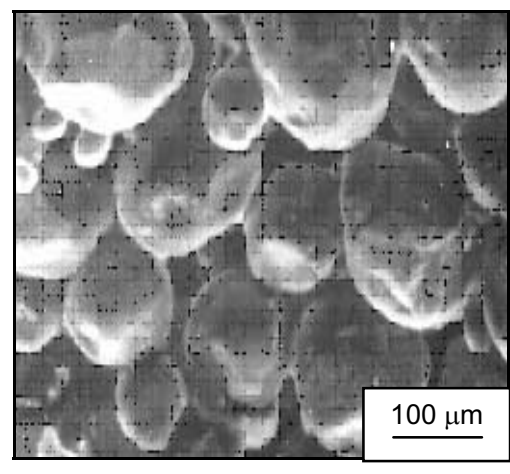

$b$

Fig. 3. Appearance of particles of beryllium powder in the initial state (a) and following treatment by hydrostatic pressure of $800 \mathrm{MPa}$ (b) 


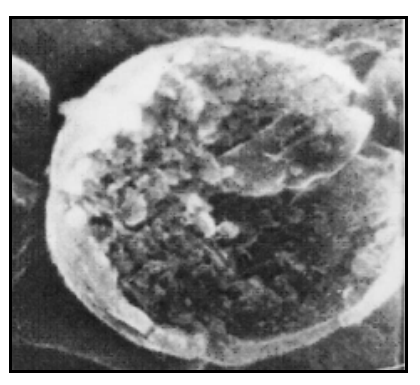

$a$

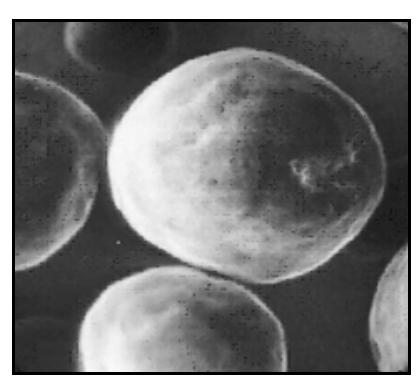

$b$

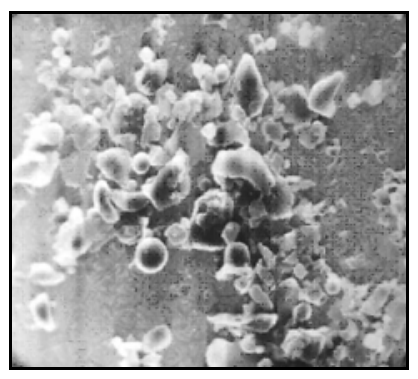

c

Fig. 4. Particle of powder with foreign inclusions on the surface (a); morphology of powder surface following treatment (b); and appearance of removed fraction $(c)(\times 1000)$

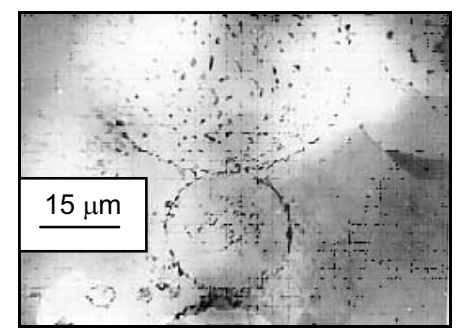

Fig. 5. Microstructure of beryllium from spherical powder with grain size $<56 \mu \mathrm{m}$

Thus, the jump in the magnitude of the strength, which is not eliminated by annealing, is related to the different substructure of the powder particles $<50$ and $>100 \mu \mathrm{m}$ in size, and is the result of an increase in the solubility of impurities in the beryllium at cooling rates of particles in the range $10^{4}-10^{5} \mathrm{deg} / \mathrm{sec}$.

Cold isostatic pressing of atomized beryllium powder cannot be used to produce compact briquettes even at a pressure of $800 \mathrm{MPa}$ (Fig. 3). By means of a scanning electron microscope it is possible to see the numerous scabs from the stronger fine particles. The smooth shape of the particles, which prevents mechanical linking under the effect of pressure, and the great strength of the small particles are responsible for this behavior of the atomized powders. Thus, powders with spherically shaped particles may be compacted only by means of hot pressing, thus avoiding the cold isostatic pressing.

Beryllium powders that have been produced by atomization of a melt are characterized by sufficiently high purity (99.3-99.5\%). In addition, thin brittle layers containing beryllium oxide and slag form on the surface of the particles. Processes for the purification of the surface of the powder particles and for the removal of particles with size $<5 \mu \mathrm{m}$ and enriched with impurities from the mass of the powder have been developed and introduced into the production cycle (Fig. 4). This has made it possible to obtain powder that is of significantly greater purity, containing less oxide than powder that has been obtained by any other method. The particles of the powder possess a rounded shape and when pouring into special containers and die molds accompanied by vibrocompaction they will pack with an arbitrary orientation. As a consequence, the mechanical properties of the compact metal produced from such powder are more uniform. Differences in the properties of the samples and in their scatter decrease in the course of testing both in the direction of pressing as well as transverse to this direction. Thus, an increase in the purity of the material and a decrease in structural anisotropy lead to a $5-5.5 \%$ growth in tensile elongation.

Hot isostatic pressing of beryllium powders with spherically shaped particles leads to the production of compact metal by uniform application of pressure, which prevents the creation of texture in the material. Moreover, by means of this method it is possible to reduce the pressing temperature with increase the pressure, which tends to preserve the substructure of powder that has been obtained with a high rate of cooling.

A cellular structure with uniform distribution of the hardening intermetallic phases is achieved. At the same time agglomerations of inclusions of $\mathrm{BeO}$ at the grain boundaries and their penetration into the grain are eliminated, 

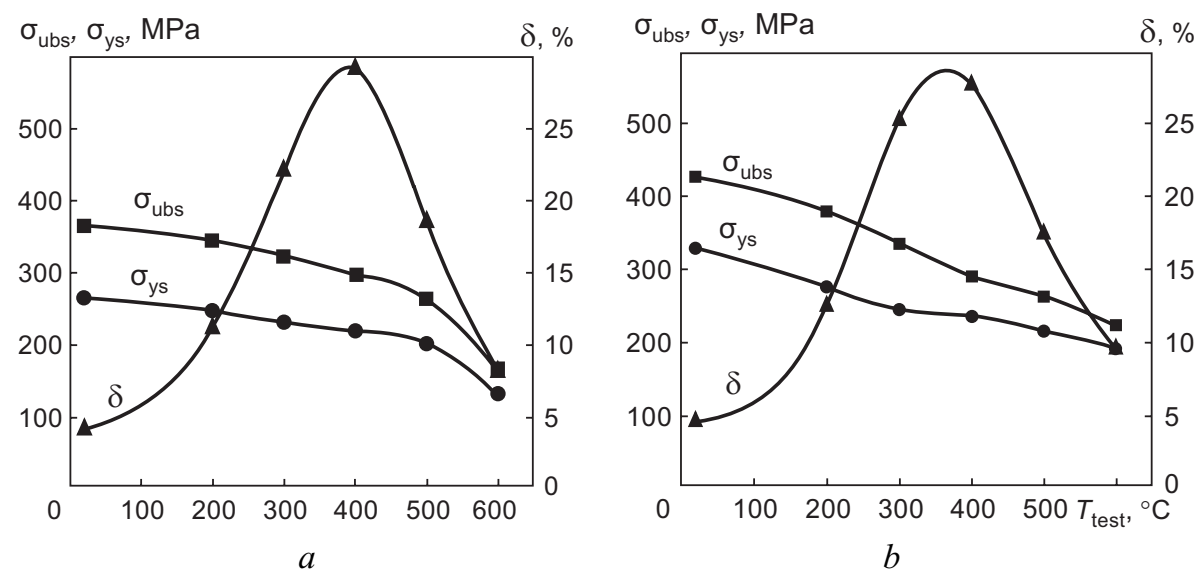

Fig. 6. Temperature dependence of mechanical properties of beryllium produced by hot isostatic pressing of atomized powders of distilled (a) and technical-grade (b) metal: $T_{\mathrm{pr}}=1030^{\circ} \mathrm{C}, P_{\mathrm{pr}}=140 \mathrm{MPa}, \tau=1.5 \mathrm{~h}$

events which tend to stabilize the structure (Fig. 5). These factors make it possible to additionally control the substructure and the properties of the materials obtained.

A mathematical model of compaction of beryllium powder has been developed and the rates of densification for different mechanisms in hot isostatic pressing have been calculated. Flow process diagrams of hot isostatic pressing for different temperatures, pressures, and powder particle sizes have been constructed. The contribution of all of the functioning mechanisms of densification to the relative density of the billet has been determined and the dependence of these mechanisms on pressure and temperature constructed. Thus, the regimes of hot isostatic pressing of atomized beryllium powders have been optimized for the production of compact billets $[6,7]$.

It has been shown that $100 \%$ density of the material of the billet is achieved for all the indicated process parameters of the compaction procedure $\left(T_{\mathrm{pr}}=800-1100^{\circ} \mathrm{C}, P_{\mathrm{pr}}=80-140 \mathrm{MPa}, \tau_{\mathrm{pr}}=1.5-4 \mathrm{~h}\right)$. The best strength and plastic characteristics of compact distilled beryllium produced from atomized powders with particle sizes $<56 \mu \mathrm{m}$ are assured by hot isostatic pressing at $1030^{\circ} \mathrm{C}$ for $1.5 \mathrm{~h}$ (Fig. 6).

Thus, through use of the hot isostatic pressing of powers with spherically shaped particles isotropic beryllium with the following mechanical characteristics was obtained: $\sigma_{\mathrm{ubs}}=429 \mathrm{MPa}, \sigma_{\mathrm{ys}}=322 \mathrm{MPa}$, and $\delta=5.2 \%$ at room temperature; $\sigma_{\mathrm{ubs}}=285 \mathrm{MPa}, \sigma_{\mathrm{ys}}=235 \mathrm{MPa}$, and $\delta=28 \%$ at $400^{\circ} \mathrm{C}$. The strength of the material was $20 \%$ higher, and its plasticity two to three times higher, than that of industrial-grade hot-pressed beryllium. Among its additional

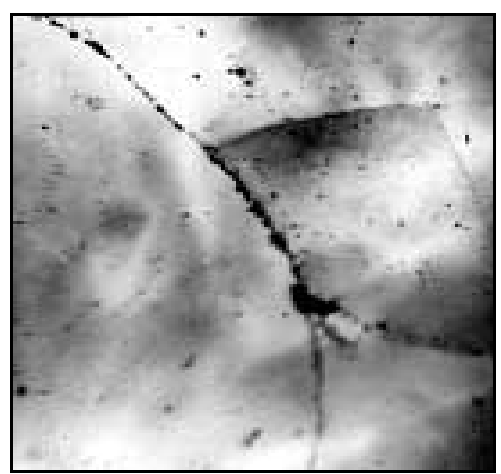

$a$

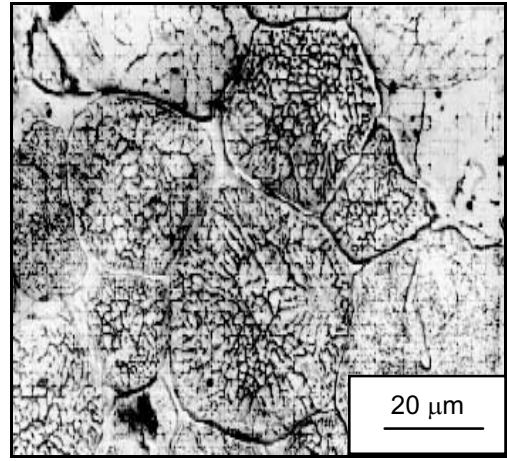

$b$

Fig. 7. Microstructure of material obtained by hot isostatic pressing (a) and its macrostructure following pickling to detect the nature of the crystallization of the particles in cooling (b): $T_{\mathrm{pr}}=$ $=1000^{\circ} \mathrm{C}$, particle size $<56 \mu \mathrm{m}$ 


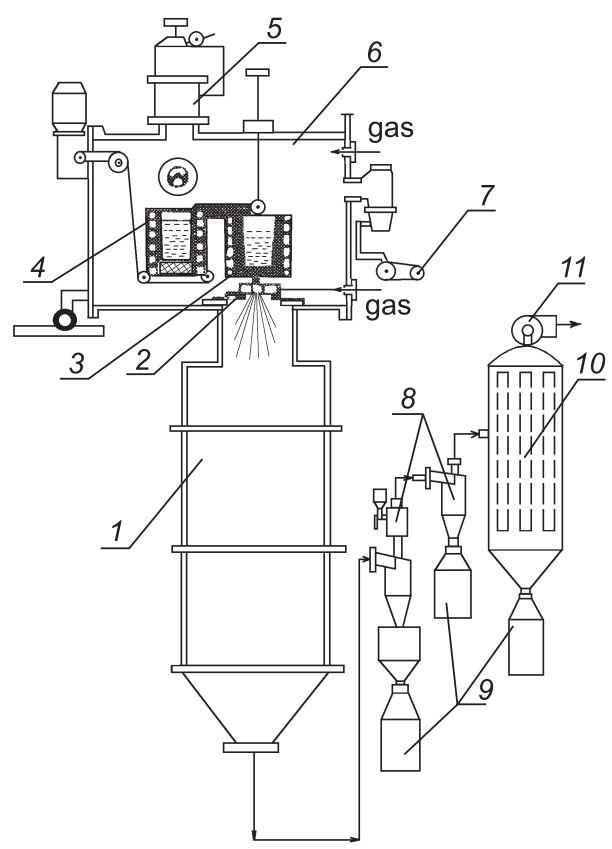

Fig. 8. Flow chart of vacuum atomization plant intended for the production of beryllium powders and alloys based on beryllium: 1) atomization column; 2) nozzle; 3) metal reservoir; 4) inductor with melting crucible; 5) loading unit; 6) melting chamber; 7) vacuum system; 8) powder catcher system; 9) powder

collector; 10) bag filter; 11) ventilators

advantages we may cite its high degree of isotropicity, the absence of pores, thermal stability, and high corrosion resistance [8].

The substructure, nature of destruction, and phase composition of beryllium billets that had been pressed at different temperatures and tested under different conditions was studied in detail. It was established that the higher strength and plasticity characteristics of the billets are connected with the elevated purity of the initial powder, the high rate of cooling of the particles, the presence of a cellular substructure, as well as a more uniform distribution of particles of the secondary phases (Figs. 5,7).

Research in the area of powder metallurgy of beryllium has not been limited to studies in physical metallurgy. A series of Sfera-type plants (Fig. 8) for the production of beryllium powders and multicomponent alloys based on beryllium by means of atomization of a melt have been developed, manufactured, and tested.

A semicontinuous cycle plant is used under factory conditions, and a technology for producing spherical particles of beryllium and alloys based on beryllium ( $\mathrm{Be}-\mathrm{Al}, \mathrm{Be}-\mathrm{Al}-\mathrm{Mg}$ ) of different granulometric composition through use of the method of atomization of a melt has been brought to a commercial level. An integrated technology for the production of beryllium and beryllium-based alloys based on fundamental technological processes, including distillation of metal, atomization of a melt by high-speed gas flow, and isostatic pressing, has been brought to a commercial level. The technology includes not only a line for production of powder with spherically shaped particles, but also a line for re-grinding of large hard-temperred granules by means of mechanical grinding, including jet grinding, with subsequent hot isostatic pressing of the powders.

High-porosity, high-strength materials [9] and compact, complexly shaped articles [10] with high utilization factor of the metal have been produced from powders of beryllium with spherically shaped particles using the technologies developed at the institute. By means of hot deformation treatment, atomized spherical powders of beryllium and the alloys $\mathrm{Be}-\mathrm{Al}$ and $\mathrm{Be}-\mathrm{Al}-\mathrm{Mg}$ may be directly transformed into semi-finished articles of specified shape, avoiding the need for a preliminary stage of pressing of the billet. 


\section{REFERENCES}

1. A. V. Babun, V. V. Savchuk, Yu. V. Shakhvorostov, and Ph. S. Tuganbayev, "Experience of commerical production of spherical powders from beryllium and its alloys at Ulba metallurgical plant," 5th IEA International Workshop on Beryllium Technology for Fusion (October 10—12, 2001, Moscow), Moscow (2001) pp. 16-19.

2. G. F. Tikhinskij, I. I. Papirov, A. V. Babun, et al., "New beryllium materials on atomized powders," Powder Metall., 37, No. 3, 222-224 (1994).

3. G. F. Tikhinskii, I. I. Papirov, A. V. Babun, et al., "New beryllium materials based on atomized beryllium powders," Poroshk. Metall., Nos. 11-12, 103-106 (1995).

4. V. M. Azhazha, A. V. Babun, and K. V. Kovtun, "Beryllium-aluminum alloys on a base of atomized powders with spherically shaped particles," Equipment and Technologies for Heat Treatment of Metals and Alloys in Machine Construction. Proc. Scientific and Applied Symposium, Khar'kov Physicotechnical Institute, Khar'kov (2000), pp. 243-246.

5. A. V. Babun, G. G. Bobylev, A. A. Vasil'ev, et al., "A study of the physical and technological properties of atomized beryllium powders with spherically shaped particles," Vopr. Atom. Nauki i Tekhniki. Ser. Fiz. Radiats. Povrezh. i Radiats. Materialovedenie, 6, No. 72, 73-77 (1998).

6. A. V. Babun, Development of High-Purity Beryllium Materials of New Generation by the Methods of Vacuum Distillation, Superrapid Quenching and Isostatic pressing for Gyroscopic Devices, Metal Optics, Hyperconductors, Project STCU, KIPT (Khar'kov), No. 290 (1999), 267 pp.

7. G. F. Tikhinskij, A. V. Babun, I. I. Papirov, et al., "New beryllium materials," J. Nuclear Mat., 233-237, 828831 (1996).

8. A. V. Babun, "Corrosion resistance of new beryllium materials based on atomized powders," Metalloved. $i$ Term. Obrabot. Metallov, No. 4, 38-42 (2000).

9. A. V. Babun, "Porous beryllium materials made from sprayed powders," Func. Mat., 7, No. 2, 361-363 (2000).

10. A. V. Babun, "Compact beryllium materials in the form of complexly shaped semi-finished articles for erospace applications," Vopr. Proektir. i Proiz. Letat. Apparatov (Khar'kov Aviats. In-t), Issue 20 (3), 63-69 (2000). 